\title{
Heavy Metal Resistant Endophytic Fungi Isolated from Nypa fruticans in Kuching Wetland National Park
}

\author{
Jenny Choo ${ }^{1 *}$, Nuraini Binti Mohd Sabri' ${ }^{2}$, Daniel Tan ${ }^{1}$, Aazani Mujahid ${ }^{2}$, and Moritz Müller ${ }^{1}$ \\ ${ }^{1}$ Faculty of Engineering, Computing and Science, Swinburne University of Technology, Sarawak campus, 93350 Kuching, Sarawak, \\ Malaysia \\ ${ }^{2}$ Department of Aquatic Science, Faculty of Resource Science and Technology, Universiti Malaysia Sarawak, 93400 Kota \\ Samarahan, Sarawak, Malaysia
}

Received 30 June 2014; Revised 17 November 2014; Accepted 17 January 2015

(C) KSO, KIOST and Springer 2015

\begin{abstract}
Heavy metal pollution is an environmental issue globally and the aim of this study was to isolate endophytic fungi from mangrove wetlands of Sarawak to assess and test their ability to grow in the presence of various heavy metals (copper $(\mathrm{Cu})$, zinc $(\mathrm{Zn})$, lead $(\mathrm{Pb})$, and chromium (Cr)). Samples of Nypa fruticans were collected from Kuching Wetland National Park (KWNP) for subsequent endophyte isolation. Ninety-three (93) isolates were obtained and assessed and the most resistant isolates (growing at concentrations up to $1000 \mathrm{ppm}$ ) were identified using fungal primers ITS 1 and ITS 4 . All of the endophytic fungi were identified to be closely related to Pestalotiopsis sp. and this is to our knowledge the first study reporting the ability of Pestalotiopsis sp. to grow at high concentrations of copper, lead, zinc and chromium. Our results highlight the potential of using endophytic fungi for the treatment of heavy metal pollution, for example as biosorbents.
\end{abstract}

Key words - heavy metals, endophytic fungi, Kuching Wetlands National Park, Nypa fruticans

\section{Introduction}

Heavy metals are released in many areas near urban complexes, metalliferous mines or major road systems due to the rapid growth of industrial activities and technological development (Alloway et al. 1995). The current pattern of industrial activity has led to a continuous increase of heavy metal discharge into the environment including cadmium, lead, chromium, copper and nickel (Hemambika et al. 2011). This will eventually cause the soil, surface waters, ground water and sediments to be contaminated and become toxic,

\footnotetext{
*Corresponding author. E-mail: jccy89@gmail.com
}

and inevitably cause a significant threat to human health.

In Malaysia, agriculture, manufacturing industry, sewage and vehicle emissions have been the main contributors of heavy metal pollution. According to Shazili et al. (2006), studies have shown that the sediments of the Juru River in Penang have been polluted with $\mathrm{Pb}\left(117 \mu \mathrm{g} \mathrm{g}^{-1}\right.$ dry wt. $)$ and Zn (483 $\mu \mathrm{g} \mathrm{g}^{-1}$ dry wt.), while the Langat River in Negeri Sembilan was found to be highly polluted with $\mathrm{Zn}$ (71-374 $\mu \mathrm{g} \mathrm{g}^{-1}$ dry wt.) and Cd (3.0 - $37.9 \mu \mathrm{g} \mathrm{g}^{-1}$ dry wt.). According to Nriagu (1980), Pacyna (1986) and Nriagu and Pacyna (1988), $\mathrm{Pb}$ was emitted globally into water at 138 thousand metric tons, $\mathrm{Zn}$ was emitted at 226 thousand metric tons, while $\mathrm{Cr}$ and $\mathrm{Cu}$ were emitted at 142 and 112 thousand metric tons in the 1980s, respectively. This clearly shows that heavy metal pollution has been one of the major environmental problems not only locally but globally for the past years.

Several conventional physico-chemical approaches have been used for the removal and treatment of heavy metal pollution sites such as electrochemical treatment, ion exchange, precipitation, reverse osmosis, evaporation and sorption (Kadirvelu et al. 2002; Luo et al. 2010). However, these methods are reported to be uneconomical and ineffective and often result in incomplete metal removal, high reagent and energy requirements and generation of toxic sludge (Hemambika et al. 2011). Bioremediation on the other hand offers a promising and economical option to treat heavy metal in contaminated sites (Iskandar et al. 2011). One of the processes, biosorption, involves the removal of 